Magazine of Concrete Research Volume 69 Issue 3

A rigorous analytical model for shrinkage cracking of reinforced concrete $\mathrm{Ng}$ and Kwan

\title{
A rigorous analytical model for shrinkage cracking of reinforced concrete
}

\section{Pui-Lam Ng}

Department of Civil Engineering, The University of Hong Kong, Pokfulam, Hong Kong, China; Faculty of Civil Engineering, Vilnius Gediminas Technical University, Vilnius, Lithuania (corresponding author: irdngpl@gmail.com)

\author{
Albert Kwok-Hung Kwan \\ Department of Civil Engineering, The University of Hong Kong, Pokfulam, \\ Hong Kong, China
}

Concrete shrinks as it dries. If its shrinkage movement is restrained, it can crack, causing serviceability and durability problems. To ensure satisfactory performance of a reinforced concrete (RC) structure, the shrinkage crack widths are generally controlled to within acceptable limits by providing steel reinforcement for crack control. However, due to unavoidable empiricism, the design guidelines given in the various design codes for computing the amount of crack-control steel are rather inconsistent. Moreover, the various existing models for prediction of crack widths do not agree with each other, indicating that the shrinkage cracking phenomenon is still far from fully understood. With the aim of resolving this problem, a rigorous analytical model for shrinkage cracking of RC is presented. The governing equations are first derived purely based on the mechanics of the steel bar-concrete interaction. The governing equations are then solved analytically without making any unjustified assumptions. Finally, the analytical model is validated through analysis of experimental results from the literature.

\section{Notation}

$A_{\text {c }} \quad$ concrete section area

$A_{\mathrm{s}} \quad$ steel area

$E_{\mathrm{c}} \quad$ elastic modulus of concrete

$E_{\mathrm{c}}^{*} \quad$ effective elastic modulus of concrete

$E_{\mathrm{s}} \quad$ elastic modulus of steel

$f_{\mathrm{b}} \quad$ average bond strength

$f_{\text {cc }} \quad$ cylinder compressive strength of concrete

$f_{\text {ct }}$ tensile strength of concrete

bond stiffness

length of concrete member between restraints

bond force transfer length

maximum crack spacing

minimum crack spacing in BS 8007 (BSI, 1987)

upper limit of bond force transfer length

bond force transfer length

upper limit of bond force transfer length in the model of Häußler-Combe and Hartig (2012)

minimum crack spacing in the model of Nejadi and

Gilbert (2004)

modular ratio

effective modular ratio

number of steel bars

number of cracks

number of transfer lengths

bond slip

crack spacing

bond slip at peak bond stress $u_{\mathrm{c}} \quad$ displacement of concrete

$u_{\mathrm{s}} \quad$ displacement of steel

w crack width

$w_{\max } \quad$ maximum crack width

$x \quad$ distance from crack

$\beta_{\mathrm{t}} \quad$ constant empirical factor describing the shape of the steel stress distribution along the transfer length proportionality constant change in member length due to support movement change in steel stress between the two ends of transfer length effective strain imposed strain mean strain of concrete shrinkage strain ultimate concrete shrinkage strain mean strain of steel maximum bond slip steel ratio average stress in uncracked concrete concrete stress mean concrete stress concrete stress at distance of $l_{0}$ from the crack final concrete stress at distance of $l_{0}$ from the crack steel stress mean steel stress maximum steel stress steel stress at distance of $l_{0}$ from the crack 


$\begin{array}{ll}\sigma_{\mathrm{s} 2} & \text { steel stress at crack } \\ \sigma_{\mathrm{s} 2}^{*} & \text { final steel stress at crack } \\ \tau_{\mathrm{b}} & \text { bond stress } \\ \tau_{\mathrm{m}} & \text { mean bond stress } \\ \tau_{\mathrm{p}} & \text { peak bond stress } \\ \phi & \text { steel bar diameter } \\ \phi_{\mathrm{c}} & \text { creep coefficient } \\ \phi_{\mathrm{c}}^{*} & \text { final creep coefficient }\end{array}$

\section{Introduction}

The shrinkage of concrete after hardening is to some extent unavoidable. In a long reinforced concrete (RC) structure restrained at the ends from longitudinal movement, such as a podium floor deck connected at each end to a rigid core wall, the shrinkage-induced tensile stress could exceed the tensile strength of concrete, thus resulting in the formation of shrinkage cracks. Shrinkage cracks are typically through cracks (i.e. cracks going through the whole thickness of the concrete section) that allow not only the ingress of moisture and deleterious chemicals to reach the steel reinforcing bars, but also create paths of water leakage from the upper floor to the lower floor. Such shrinkage cracking could pose serviceability and durability problems. To ensure satisfactory performance of RC structures, the shrinkage crack widths must be controlled to within acceptable limits (Castel and Gilbert, 2014; Hughes, 1971a, 1971b). However, to do so, the crack widths need to be evaluated in the first place.

Shrinkage cracking may be alleviated or controlled by a number of measures (Kwan et al., 2002, 2003). Basically, these include the provision of movement joints, the provision of latecast strips, the use of high-performance concrete with better dimensional stability, the addition of expanding or shrinkage reducing agents to the concrete mix, and the provision of crack-control steel reinforcement. The provision of crackcontrol steel, which does not affect construction scheduling, is the most commonly adopted among these measures. However, the relationships between the concrete tensile strength, the ultimate shrinkage strain, the crack-control steel provided and the resulting crack spacings and crack widths are still not well understood. Fairly high levels of empiricism and conservatism have been adopted in various design guides and codes such as British standard BS 8007 (BSI, 1987). As a result, the amount of crack-control steel to be provided is often quite large.

After cracking, the shrinking concrete tends to move away from the cracks and this tendency is opposed by the crackcontrol steel through the steel bar-concrete bond. It limits the shrinkage movement of the concrete and thus reduces the crack widths to smaller values. Although at the cracks the concrete tensile stresses are relieved to zero, the bond action would still induce tensile stresses in the concrete, which are generally larger at greater distance from the nearest crack. As the shrinkage further increases, the tensile stresses in between two

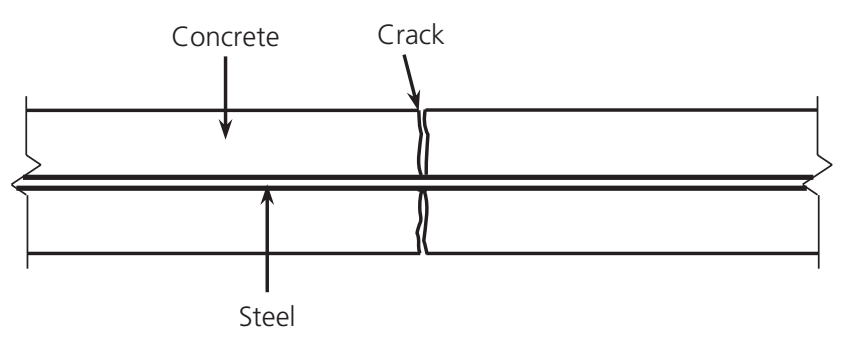

(a)

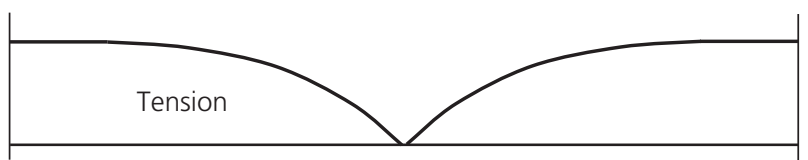

(b)

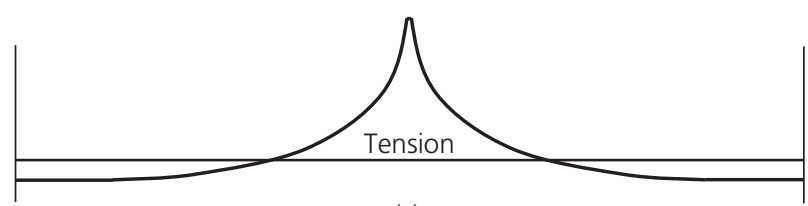

(c)

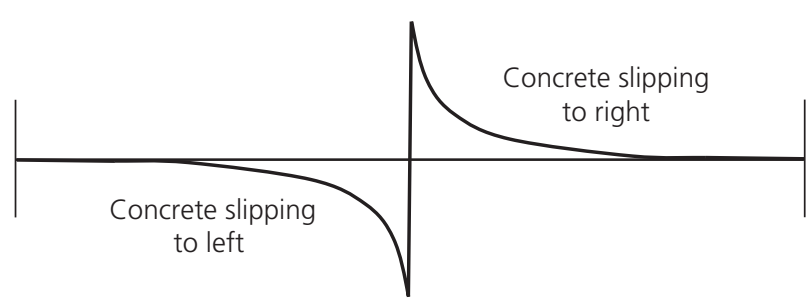

(d)

Figure 1. Stress distributions across a shrinkage crack: (a) cracked RC member; (b) concrete stress; (c) steel stress; (d) bond stress

existing cracks increase and eventually can become large enough to cause the formation of a new crack. In general, the provision of more crack-control steel would lead to the formation of more cracks with smaller crack widths. On the other hand, the shrinkage movement of the concrete pulls the crack-control steel away from the cracks through the steel bar-concrete bond. As a result, the crack-control steel would be subjected to much higher tensile stresses at the cracks than at other locations. Figure 1 illustrates the spatial distributions of concrete, steel and bond stresses across a shrinkage crack.

Some simple formulas for the determination of the crack spacing and crack width are given in BS 8007 (BSI, 1987). These formulas are based on the assumption that the bond stress is uniform near the cracks. While such an assumption is rather empirical and might not be justified, it has the advantage of being simple to use. Gilbert $(1992,2001)$ developed an analytical model for evaluating shrinkage cracking in fully restrained concrete members. It is based on the assumption that the concrete, steel and bond stresses would vary along the 
length only within a certain distance from the crack. This distance is evaluated using an empirical expression in terms of only the crack-control steel ratio and diameter. However, in some cases, the computed crack spacing could be unreasonably large or small. Gilbert (2003) and Nejadi and Gilbert (2004) later improved this model by modifying the previous formulas. More recently, Häußler-Combe and Hartig (2012) proposed another analytical model based on certain empirical coefficients for evaluating the crack spacing and crack width. Their model was validated using the experimental results reported by Nejadi and Gilbert (2004).

Apart from these analytical models, finite-element models have also been developed to analyse the shrinkage movement and cracking of RC structures (Jurkiewiez et al., 1999; Kwan and $\mathrm{Ng}, 2009$; Liu et al., 2006). In the finite-element models, time step analyses were applied to evaluate the spatial and temporal variations of the bond, concrete and steel stresses. Theoretically, the finite-element models should be more rigorous and generally applicable. However, with the bond slip at the steel bar-concrete interface ignored, the concrete and steel bars modelled as an integrated continuum and the cracks modelled as smeared cracks rather than as discrete cracks, these finite-element models are not capable of giving the crack spacing and crack width in the computed results (Ma and Kwan, 2015). For these reasons, the evaluation of the amount of crack-control steel needed and the resulting crack spacing and crack width still cannot be carried out using the finiteelement method.

To rationalise the design of steel for the control of shrinkage cracking, the relationships between the material properties, the ratio and diameter of the crack-control steel, crack spacing and crack width need to be established. A rigorous analytical model for shrinkage cracking of RC is developed in this paper based on a set of governing differential equations. By solving the governing differential equations analytically, closed-form solutions are obtained, from which the effects of various structural parameters on the crack spacing and crack width may be evaluated algebraically and the crack-control steel needed may be evaluated directly.

\section{Shrinkage and creep of concrete}

As shrinkage takes place and tensile stresses are induced in concrete due to movement restraint, creep also occurs, thus relieving parts of the shrinkage-induced tensile stresses through relaxation (Kwan and $\mathrm{Ng}$, 2015). Both shrinkage and creep are time-dependent, as explained in the following section.

There are two main types of concrete shrinkage - autogenous shrinkage and drying shrinkage (Neville, 2011). Autogenous shrinkage is caused by self-desiccation, whereas drying shrinkage is caused by loss of water due to evaporation. Generally, autogenous shrinkage is fairly small compared with drying shrinkage. Since the loss of water over time depends on the permeability of the concrete, the size of the concrete member and the environmental conditions, the rate of drying shrinkage is also dependent on these factors (Kwan et al., 2010). On the other hand, there are two dominant mechanisms of concrete creep. The first mechanism is viscous sliding of the C-S-H (calcium silicate hydrate) gel particles (Neville, 1958; Vandamme and Ulm, 2009). The second mechanism is the internal movement of adsorbed or intra-crystalline water, which is believed to be caused mainly by changes in the hygral equilibrium within the pore structure of the gel inside concrete (Neville, 1955; Powers, 1968). As for drying shrinkage, the rate of creep is also dependent on the permeability of the concrete, the size of the concrete member, and the environmental conditions.

However, it takes many months to measure the shrinkage and creep of a particular concrete. Therefore, in usual practice, the shrinkage strain is just evaluated using the shrinkage coefficient given in design codes and the creep effect is taken into account by changing the elastic modulus to the long-term elastic modulus, which may be evaluated using the creep coefficient given in design codes (Gilbert and Ranzi, 2011).

\section{Bond stress-slip constitutive model}

At the steel bar-concrete interface, bond slip occurs and bond stresses are developed. The bond stiffness of the interface affects the effectiveness of the crack-control steel and should thus be properly accounted for. For the bond stress-slip relation, CEB-FIP Model Code 1990 (hereafter referred to as MC-90) (CEB, 1993) gives the bond stress-slip curve shown in Figure 2. According to MC-90, if ribbed steel bars are used (plain round bars are rarely used nowadays because of inferior bond), the bond slip at which peak bond stress would be developed is $0.6 \mathrm{~mm}$, regardless of whether the concrete is

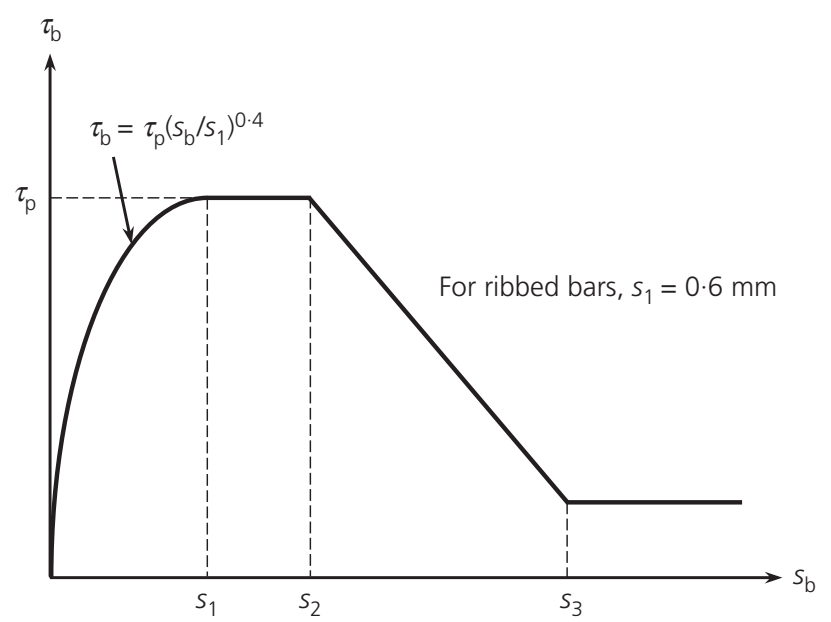

Figure 2. Bond stress-slip curve given in MC-90 (CEB, 1993) 
unconfined or confined. Such a bond slip value of $0.6 \mathrm{~mm}$ is actually quite large. As the crack width is twice the bond slip, and the allowable crack width is generally not larger than $0.3 \mathrm{~mm}$, the bond slip at the serviceability limit state has to be controlled to within $0.5 \times 0.3 \mathrm{~mm}=0 \cdot 15 \mathrm{~mm}$. Basically, before the peak bond stress is developed, the bond stress is an increasing function of the bond slip. Herein, for simplicity, the bond stress is assumed to be proportional to the bond slip and the bond stiffness $k_{\mathrm{b}}$ is taken to be the mean secant stiffness, as evaluated below. As per MC-90, at bond slip $s_{\mathrm{b}}$ not larger than that giving the peak bond stress, the bond stress $\tau_{\mathrm{b}}$ is related to the peak bond stress $\tau_{\mathrm{p}}$ by

1. $\tau_{\mathrm{b}}=\tau_{\mathrm{p}}\left(s_{\mathrm{b}} / s_{1}\right)^{0.4}$

where $s_{1}$ is the bond slip at peak bond stress. The secant bond stiffness is equal to $\tau_{\mathrm{b}} / s_{\mathrm{b}}$ and the mean secant stiffness within the range of bond slip from $0 \cdot 02 s_{\mathrm{b}}$ to $s_{\mathrm{b}}$ may be evaluated from Equation 2 (the bond stiffness in MC-90 is unreasonably or even infinitely large at very small bond slip and therefore is not included in the evaluation).

2. $k_{\mathrm{b}}=\frac{1}{0 \cdot 98 s_{\mathrm{b}}} \int_{0.02 s_{\mathrm{b}}}^{s_{\mathrm{b}}} \tau_{\mathrm{p}} \frac{\left(s_{\mathrm{b}} / s_{1}\right)^{0.4}}{s_{\mathrm{b}}} \mathrm{d} s_{\mathrm{b}}=2 \cdot 0\left(\tau_{\mathrm{p}} / s_{\mathrm{b}}\right)\left(s_{\mathrm{b}} / s_{1}\right)^{0.4}$

Regarding the peak bond stress $\tau_{\mathrm{p}}$, MC-90 suggests that it may be taken as $2 \cdot 0\left(f_{\mathrm{cc}}\right)^{0.5}$ for unconfined concrete or as $2 \cdot 5\left(f_{\mathrm{cc}}\right)^{0.5}$ for confined concrete, where $f_{\mathrm{cc}}$ is the cylinder compressive strength of the concrete.

\section{Existing methods of shrinkage cracking analysis}

Three common methodologies for shrinkage cracking analysis - the method given in BS 8007 (BSI, 1987), the model developed by Nejadi and Gilbert (2004) and the model developed by Häußler-Combe and Hartig (2012) - are highlighted in this section.

\section{The BS 8007 method}

At a crack, the concrete stress is zero. Assuming uniform bond stress near the crack, the concrete stress $\sigma_{\mathrm{c}}$ at a distance $l$ from the crack is equal to

3. $\sigma_{\mathrm{c}}=\frac{l(n \pi \phi) f_{\mathrm{b}}}{A_{\mathrm{c}}}=l\left(\frac{4 \rho}{\phi}\right) f_{\mathrm{b}}$

where $n$ is the number of steel bars, $\phi$ is the steel bar diameter, $\rho$ is the steel ratio, $f_{\mathrm{b}}$ is the average bond strength and $A_{\mathrm{c}}$ is the concrete section area. The concrete would crack again at a minimum distance from the existing crack of $l_{\min }$, where $\sigma_{\mathrm{c}}$ reaches the tensile strength of concrete $f_{\mathrm{ct}}$. Based on this condition, the minimum crack spacing $l_{\text {min }}$ may be obtained as

4. $\quad l_{\min }=\left(\frac{\phi}{4 \rho}\right)\left(\frac{f_{\mathrm{ct}}}{f_{\mathrm{b}}}\right)$

Between two existing cracks, the concrete stress increases from zero at one crack to a maximum value at mid-distance between the two cracks and then decreases to zero at the other crack. If the distance between the two existing cracks is longer than $2 l_{\min }$, the maximum concrete stress would be higher than the tensile strength and a new crack would be formed between the two existing cracks. Hence, the maximum crack spacing $l_{\text {max }}$ may be taken as

5. $\quad l_{\max }=2 l_{\min }=\left(\frac{\phi}{2 \rho}\right)\left(\frac{f_{\mathrm{ct}}}{f_{\mathrm{b}}}\right)$

From the above, the maximum crack width $w_{\max }$ is derived as

6. $w_{\max }=l_{\max } \varepsilon$

where $\varepsilon$ is the effective strain evaluated as the sum of shrinkage strain and thermal contraction strain deducted by 100 micro-strain as stipulated in BS 8007 (BSI, 1987). For type 2 deformed bars, the ratio $\left(f_{\mathrm{ct}} / f_{\mathrm{b}}\right)$ may be taken as $0 \cdot 67$.

From the above, the following important characteristics of the method are noted.

- It is assumed that full bond strength would be developed along the steel bar-concrete interface. However, as can be seen from Figure 2, for ribbed bars, this is generally not possible unless the bond slip is larger than $0.6 \mathrm{~mm}$ or, in other words, the crack width is larger than $1.2 \mathrm{~mm}$. Such an assumption would lead to overestimation of the bond stress and underestimation of the crack spacing.

- The predicted crack spacing is independent of the effective strain.

- The predicted crack width increases with the effective strain.

\section{Model proposed by Nejadi and Gilbert}

According to the model of Nejadi and Gilbert (2004), the concrete stress varies from zero at the crack to $\sigma_{\mathrm{c} 1}$ at a distance of $l_{0}$ from the crack and then remains constant at further distance from the crack. On the other hand, the steel stress varies from $\sigma_{\mathrm{s} 2}$ at the crack to $\sigma_{\mathrm{s} 1}$ at a distance of $l_{0}$ from the crack and then remains constant at further distance from the crack. At the first crack, $l_{0}$ may be evaluated as $l_{0}=\phi /(10 \rho)$, but at the final or long-term stage, the value of $l_{0}$ should be multiplied by 1.33 to become $\phi /(7 \cdot 5 \rho)$ so as to cater for the deterioration 
in bond with time. The distance $l_{0}$ may be interpreted as the minimum crack spacing.

After first cracking, the concrete stress $\sigma_{\mathrm{c} 1}$ at distance $l_{0}$ from the crack and the steel stress $\sigma_{\mathrm{s} 2}$ at the crack are derived as follows (Gilbert, 1992, 2001, 2003)

7. $\sigma_{\mathrm{c} 1}=\frac{(3 L) m \rho f_{\mathrm{ct}}}{2 l_{0}+(3 L) m \rho}$

8. $\sigma_{\mathrm{s} 2}=\frac{\left(3 L-2 l_{0}\right) m f_{\mathrm{ct}}}{2 l_{0}+(3 L) m \rho}$

where $L$ is the length of the concrete member between restraints, $m$ is the modular ratio $\left(E_{\mathrm{s}} / E_{\mathrm{c}}\right)$ and $\rho$ is the steel ratio $\left(A_{\mathrm{s}} / A_{\mathrm{c}}\right)$. After all shrinkage has taken place and the final crack pattern is established, the final concrete stress at distance $l_{0}$ from a crack $\left(\sigma_{\mathrm{c} 1}^{*}\right)$ and the final steel stress at each crack $\left(\sigma_{\mathrm{s} 2}^{*}\right)$ become

9. $\sigma_{\mathrm{c} 1}^{*}=\frac{3 E_{\mathrm{s}} \rho \Delta u}{2 n_{\mathrm{cr}} l_{0}}-\frac{(3 L) m^{*} \rho}{2 n_{\mathrm{cr}} l_{0}}\left(\sigma_{\mathrm{av}}+\varepsilon_{\mathrm{cs}}^{*} E_{\mathrm{c}}^{*}\right) \leq f_{\mathrm{ct}}$

10. $\sigma_{\mathrm{s} 2}^{*}=\frac{3 E_{\mathrm{s}} \Delta u}{2 n_{\mathrm{cr}} l_{0}}-\frac{\left(3 L-2 n_{\mathrm{cr}} l_{0}\right) m^{*}}{2 n_{\mathrm{cr}} l_{0}}\left(\sigma_{\mathrm{av}}+\varepsilon_{\mathrm{cs}}^{*} E_{\mathrm{c}}^{*}\right)$

in which $\Delta u$ is the change in length of the member due to support movement, $n_{\mathrm{cr}}$ is the number of cracks, $\sigma_{\mathrm{av}}$ is the average stress in the uncracked concrete, $\varepsilon_{\mathrm{cs}}^{*}$ is the ultimate concrete shrinkage strain, $E_{\mathrm{c}}^{*}$ is the effective elastic modulus of concrete and $m^{*}$ is the effective modular ratio $\left(E_{\mathrm{s}} / E_{\mathrm{c}}^{*}\right)$. The average concrete stress $\sigma_{\mathrm{av}}$ may be taken as $\left(\sigma_{\mathrm{c} 1}+f_{\mathrm{ct}}\right) / 2$ in which $f_{\text {ct }}$ is the concrete tensile strength, whereas the effective elastic modulus $E_{\mathrm{c}}^{*}$ may be taken as $E_{\mathrm{c}} /\left(1+\phi_{\mathrm{c}}^{*}\right)$ in which $\phi_{\mathrm{c}}^{*}$ is the final creep coefficient. On the other hand, the number of cracks $n_{\text {cr }}$ should be taken as the smallest integer value such that $\sigma_{\mathrm{cl}}^{*} \leq f_{\mathrm{ct}}$. Lastly, provided the steel at the crack has not yielded, the final mean crack width $w$ is given by

11. $w=-\left[\frac{\sigma_{\mathrm{c} 1}^{*}}{E_{\mathrm{c}}^{*}}\left(\frac{L}{n_{\mathrm{cr}}}-\frac{2}{3} l_{0}\right)+\varepsilon_{\mathrm{cs}}^{*}\left(\frac{L}{n_{\mathrm{cr}}}\right)\right]$

The following important characteristics of the model are noted.

- The actual bond stress distribution is not evaluated as a part of the solution.

- The minimum crack spacing is dependent only on the steel bar diameter and ratio.

- The number of cracks increases, whereas the mean crack spacing decreases as the magnitude of shrinkage strain increases.
The predicted mean crack width $w$ increases with the magnitude of shrinkage strain.

\section{Model proposed by Häußler-Combe and Hartig}

Like the other models, the model developed by Häußler-Combe and Hartig (2012) assumes that there is a certain bond force transfer length at the two sides of a crack, within which the bond force at the steel bar-concrete interface would cause the concrete stresses to vary from zero at the crack to a maximum value at the end of the bond force transfer length and the steel stress, to vary from a maximum value at the crack to a minimum value at the end of the bond force transfer length.

According to this model, the crack width $w$ of a symmetrical crack can be calculated as

12. $w=2 l_{\mathrm{t}}\left(\varepsilon_{\mathrm{sm}}-\varepsilon_{\mathrm{cm}}\right)$

where $l_{\mathrm{t}}$ is the bond force transfer length, $\varepsilon_{\mathrm{sm}}$ is the mean strain of the steel and $\varepsilon_{\mathrm{cm}}$ is the mean strain of the concrete. In turn, the mean strains are evaluated from the corresponding mean stresses. Let the maximum steel stress be $\sigma_{\mathrm{sr}}$ and the change in steel stress between the two ends of the transfer length be $\Delta \sigma_{\mathrm{s}}$. The mean steel stress $\sigma_{\text {sm }}$ may be evaluated as

13. $\sigma_{\mathrm{sm}}=\sigma_{\mathrm{sr}}-\beta_{\mathrm{t}} \Delta \sigma_{\mathrm{s}}$

where $\beta_{\mathrm{t}}$ is a constant empirical factor describing the shape of the stress distribution in the steel along the transfer length. Likewise, the mean concrete stress $\sigma_{\mathrm{cm}}$ may be evaluated as

14. $\sigma_{\mathrm{cm}}=\rho \beta_{\mathrm{t}} \Delta \sigma_{\mathrm{s}}$

in which $\rho=A_{\mathrm{s}} / A_{\mathrm{c}}$ is the steel ratio. The force transfer between the steel bar and concrete is effected by the bond stresses developed along the transfer length. Based on equilibrium

15. $\Delta \sigma_{\mathrm{s}}=\frac{n \pi \phi}{A_{\mathrm{s}}} l_{\mathrm{t}} \tau_{\mathrm{m}}=\left(\frac{4}{\phi}\right) l_{\mathrm{t}} \tau_{\mathrm{m}}$

where $n$ is the number of steel bars and $\tau_{\mathrm{m}}$ is the mean bond stress. For simplicity, it is assumed that $\tau_{\mathrm{m}}=\gamma f_{\mathrm{ct}}$, where $\gamma$ is a proportionality constant and $f_{\text {ct }}$ is the concrete tensile strength. Since the concrete stress increases from zero at the crack to a maximum value of $\rho \Delta \sigma_{\mathrm{s}}$ at the end of the transfer length, and the concrete stress cannot be larger than $f_{\mathrm{ct}}, \Delta \sigma_{\mathrm{s}}$ has a maximum value of $f_{\mathrm{ct}} / \rho$. As a result, the transfer length $l_{\mathrm{t}}$ is subjected to an upper limit of $l_{\mathrm{t}}^{*}$, which can be determined by substituting $\Delta \sigma_{\mathrm{s}}=f_{\mathrm{ct}} / \rho$ into Equation 15 , giving

16. $l_{\mathrm{t}}^{*}=\left(\frac{\phi}{4 \rho}\right)\left(\frac{f_{\mathrm{ct}}}{\tau_{\mathrm{m}}}\right)$ 
Let the crack spacing be $s_{\mathrm{r}}$. The crack spacing $s_{\mathrm{r}}$ cannot be longer than $2 l_{\mathrm{t}}^{*}$ because otherwise the maximum concrete stress $\left(=\rho \Delta \sigma_{\mathrm{s}}\right)$ occurring at the mid-point between two adjacent cracks would exceed the concrete tensile strength and a new crack would be formed. Hence, the crack spacing $s_{\mathrm{r}}$ has to satisfy the condition

17. $l_{\mathrm{t}}^{*} \leq s_{\mathrm{r}} \leq 2 l_{\mathrm{t}}^{*}$

In other words, there is a maximum crack spacing of $2 l_{\mathrm{t}}^{*}$ and a minimum crack spacing of $l_{\mathrm{t}}^{*}$.

For a RC member subjected to an imposed strain $\varepsilon_{\mathrm{cE}}<0$ over the entire length $L$ (the imposed strain could be shrinkage or thermal contraction strain) and having a total of $n_{\text {cr }}$ cracks formed in the stabilised cracking state, the mean crack width $w$ may be evaluated from Equation 18 based on the compatibility condition

18. $n_{\mathrm{cr}} w+\left(L \varepsilon_{\mathrm{cE}}+\frac{n_{\mathrm{cr}}\left(2 l_{\mathrm{t}}\right) \sigma_{\mathrm{cm}}}{E_{\mathrm{c}}}\right)=\Delta u$

in which $\Delta u$ is the change in length of the member due to support movement. Substituting the value of $\sigma_{\mathrm{cm}}=\rho \beta_{\mathrm{t}} \Delta \sigma_{\mathrm{s}}$ and the value of $l_{\mathrm{t}}=(\phi / 4)\left(\Delta \sigma_{\mathrm{s}} / \tau_{\mathrm{m}}\right)$ into the above equation and assuming that $\Delta \sigma_{\mathrm{s}}$ has its maximum value of $f_{\mathrm{ct}} / \rho$, the formula for the mean crack width $w$ under the condition of stabilised cracking is derived as

19. $w=\left(\frac{\phi}{2 \rho}\right)\left(\frac{f_{\mathrm{ct}}}{\tau_{\mathrm{m}}}\right)\left(\frac{\Delta u}{L}-\varepsilon_{\mathrm{cE}}-\beta_{\mathrm{t}} \frac{f_{\mathrm{ct}}}{E_{\mathrm{c}}}\right)$

in which $E_{\mathrm{c}}$ is the effective elastic modulus of concrete. To account for creep, the effective elastic modulus may be taken as the elastic modulus divided by the factor $\left(1+\phi_{\mathrm{c}}\right)$, where $\phi_{\mathrm{c}}$ is the creep coefficient.

This model has the following characteristics.

The actual bond stress distribution is not evaluated as a part of the solution.

- The computed results are dependent on the assumed values of the coefficients $\beta_{\mathrm{t}}$ and $\gamma$.

- Both the minimum crack spacing $l_{\mathrm{t}}^{*}$ and maximum crack spacing $2 l_{\mathrm{t}}^{*}$ are independent of the shrinkage strain.

- The computed mean crack width $w$ increases with the magnitude of shrinkage strain.

\section{A new and rigorous analytical model}

The existing methods of shrinkage cracking analysis detailed in the previous section differ widely in their formulations and are therefore not consistent with each other. Actually, none of the methods are capable of giving the actual variations of the bond, concrete and steel stresses along the $\mathrm{RC}$ member. The previous models generally assume that there is a well-defined bond force transfer length at each side of the crack and that the bond stress varies within the transfer length with a certain fixed mean bond stress. The authors of this paper do not agree with these assumptions and are of the view that evaluation of the actual variations of the bond, concrete and steel stresses should be incorporated as an integral part of the formulation, as presented below.

In the following, a RC member subjected to a shrinkage strain of $\varepsilon_{\mathrm{cs}}$ and an imposed strain of $\Delta u / L$ due to support movement ( $\Delta u$ is the change in length and $L$ is the total length) is analysed. If only one crack has formed, the segment of the member from the crack to one end of the member is considered. If two or more cracks have formed, the segment of the member from one crack to the mid-point between this crack and the adjacent crack is considered. The segment under consideration here is shown in Figure 3. The maximum bond slip $\xi$ occurs at the crack; at the end of the segment, the bond slip is equal to zero because of symmetry or end fixity. Let the distance from the crack be $x$ and the displacements of concrete and steel be $u_{\mathrm{c}}$ and $u_{\mathrm{s}}$, respectively. These displacements are related to the concrete stress $\sigma_{\mathrm{c}}$, steel stress $\sigma_{\mathrm{s}}$ and bond stress $\tau_{\mathrm{b}}$ by the equations

20. $\frac{\partial u_{\mathrm{c}}}{\partial x}=\varepsilon_{\mathrm{cs}}+\frac{\sigma_{\mathrm{c}}}{E_{\mathrm{c}}}$

21. $\frac{\partial u_{\mathrm{s}}}{\partial x}=\frac{\sigma_{\mathrm{s}}}{E_{\mathrm{s}}}$

22. $\quad u_{\mathrm{c}}-u_{\mathrm{s}}=\frac{\tau_{\mathrm{b}}}{k_{\mathrm{b}}}$

in which $E_{\mathrm{c}}$ is the elastic modulus of concrete, $E_{\mathrm{s}}$ is the elastic modulus of steel and $k_{\mathrm{b}}$ is the bond stiffness. The equilibrium condition gives rise to

23. $n \pi \phi \tau_{\mathrm{b}}=A_{\mathrm{c}} \frac{\partial \sigma_{\mathrm{c}}}{\partial x}=-A_{\mathrm{s}} \frac{\partial \sigma_{\mathrm{s}}}{\partial x}$

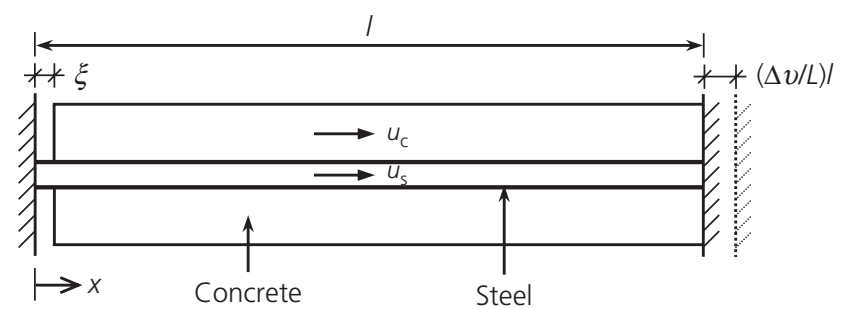

Figure 3. Segment of RC member subjected to shrinkage 
where $n$ is the number of steel bars, $\phi$ is the steel bar diameter, $A_{\mathrm{c}}$ is the concrete area and $A_{\mathrm{s}}$ is the steel area. Expressing in terms of displacements only, the following differential equation is obtained

24. $n \pi \phi k_{\mathrm{b}}\left(u_{\mathrm{c}}-u_{\mathrm{s}}\right)=E_{\mathrm{c}} A_{\mathrm{c}} \frac{\partial^{2} u_{\mathrm{c}}}{\partial x^{2}}=-E_{\mathrm{s}} A_{\mathrm{s}} \frac{\partial^{2} u_{\mathrm{s}}}{\partial x^{2}}$

Dividing the whole equation by $E_{\mathrm{c}} A_{\mathrm{c}}$ and introducing the parameter $\lambda$, which denotes the ratio

25. $\lambda=\frac{n \pi \phi k_{\mathrm{b}}}{E_{\mathrm{c}} A_{\mathrm{c}}}=\left(\frac{4 \rho}{\phi}\right)\left(\frac{k_{\mathrm{b}}}{E_{\mathrm{c}}}\right)$

Equation 24 becomes

26. $\lambda\left(u_{\mathrm{c}}-u_{\mathrm{s}}\right)=\frac{\partial^{2} u_{\mathrm{c}}}{\partial x^{2}}=-m \rho \frac{\partial^{2} u_{\mathrm{s}}}{\partial x^{2}}$

in which $m$ is the modular ratio $\left(E_{\mathrm{S}} / E_{\mathrm{c}}\right)$ and $\rho$ is the steel ratio $\left(A_{\mathrm{s}} / A_{\mathrm{c}}\right)$.

Equation 26 is the governing equation of the structural system. It is actually a set of two second-order partial differential equations, which need to be solved with the boundary conditions considered. The boundary conditions are

at the crack: $x=0, u_{\mathrm{c}}=\xi, u_{\mathrm{s}}=0$ and $\sigma_{\mathrm{c}}=0$

at the end of the segment: $x=l, u_{\mathrm{c}}=(\Delta u / L) l, u_{\mathrm{s}}=(\Delta u / L) l$ and $\sigma_{\mathrm{c}} \leq f_{\mathrm{ct}}$.

Note that $l$ is the bond force transfer length from the crack (where the bond slip is maximum) to the end of the segment (where the bond slip is equal to zero). For conciseness, the procedures of solving the governing equation together with the boundary conditions are presented in the Appendix.

As explained in the Appendix, a parameter $\psi$ is employed to solve the differential equations; $\psi$ is defined as

27. $\psi=\sqrt{\frac{\lambda(1+m \rho)}{m \rho}}$

Solving the governing equation, the concrete stress in terms of the maximum bond slip $\xi$ at the crack is obtained as

28. $\sigma_{\mathrm{c}}(x)=E_{\mathrm{c}}\left(\frac{\Delta u}{L}-\varepsilon_{\mathrm{cS}}-\xi \cdot \frac{m \rho \psi}{1+m \rho} \cdot \frac{\cosh (\psi(l-x))}{\sinh (\psi l)}-\xi \cdot \frac{1 / l}{1+m \rho}\right)$
At $x=0, \sigma_{\mathrm{c}}=0$. This boundary condition yields

29. $\frac{\Delta u}{L}-\varepsilon_{\mathrm{cs}}-\xi \cdot \frac{m \rho \psi}{1+m \rho} \cdot \frac{\cosh (\psi l)}{\sinh (\psi l)}-\xi \cdot \frac{1 / l}{1+m \rho}=0$

Solving Equation 29, the maximum bond slip $\xi$ is obtained as

30. $\quad \xi=\frac{1+m \rho}{1+(m \rho \psi l / \tanh (\psi l))}\left(\frac{\Delta u}{L}-\varepsilon_{\mathrm{cs}}\right) l$

Substituting into Equation 28, the concrete stress in terms of the shrinkage strain $\varepsilon_{\mathrm{cs}}$ is obtained as

$$
\text { 31. } \begin{aligned}
\sigma_{\mathrm{c}}(x)= & E_{\mathrm{c}}\left(\frac{\Delta u}{L}-\varepsilon_{\mathrm{cs}}\right)\left(\frac{m \rho \psi l}{m \rho \psi l+\tanh (\psi l)}\right) \\
& \times\left(1-\frac{\cosh (\psi(l-x))}{\cosh (\psi l)}\right)
\end{aligned}
$$

The variations of the concrete stress $\sigma_{\mathrm{c}}$ with the distance $x$ from the crack for some typical cases (i.e. the specimens analysed in next section) are illustrated in Figure 4 . The maximum concrete stress occurs at $x=l$ and is derived from Equation 31 as

32. $\sigma_{\mathrm{c}}(l)=E_{\mathrm{c}}\left(\frac{\Delta u}{L}-\varepsilon_{\mathrm{cs}}\right)\left(\frac{m \rho \psi l}{m \rho \psi l+\tanh (\psi l)}\right)\left(1-\frac{1}{\cosh (\psi l)}\right)$

Since the maximum concrete stress cannot be larger than the concrete tensile strength, the following inequality applies

33. $E_{\mathrm{c}}\left(\frac{\Delta u}{L}-\varepsilon_{\mathrm{cs}}\right)\left(\frac{m \rho \psi l}{m \rho \psi l+\tanh (\psi l)}\right)\left(1-\frac{1}{\cosh (\psi l)}\right) \leq f_{\mathrm{ct}}$

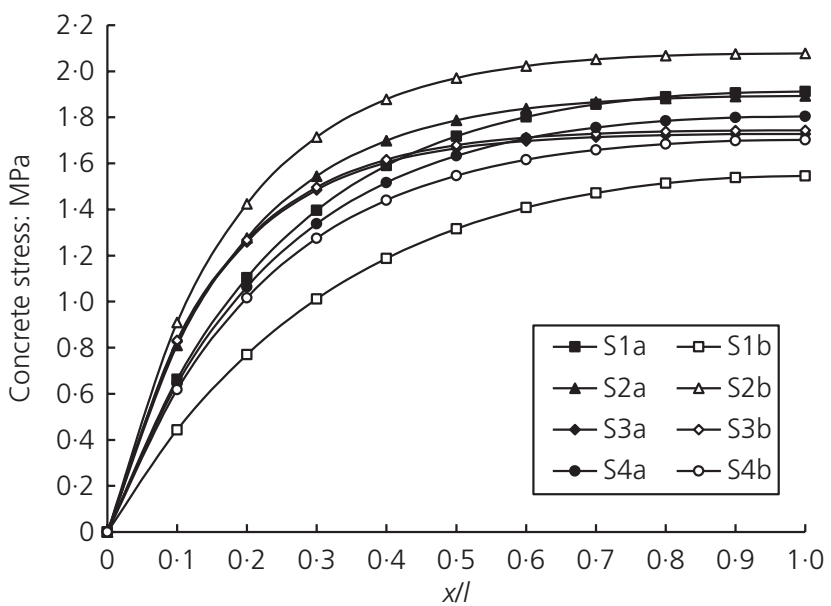

Figure 4. Variations of concrete stress with distance from a crack 

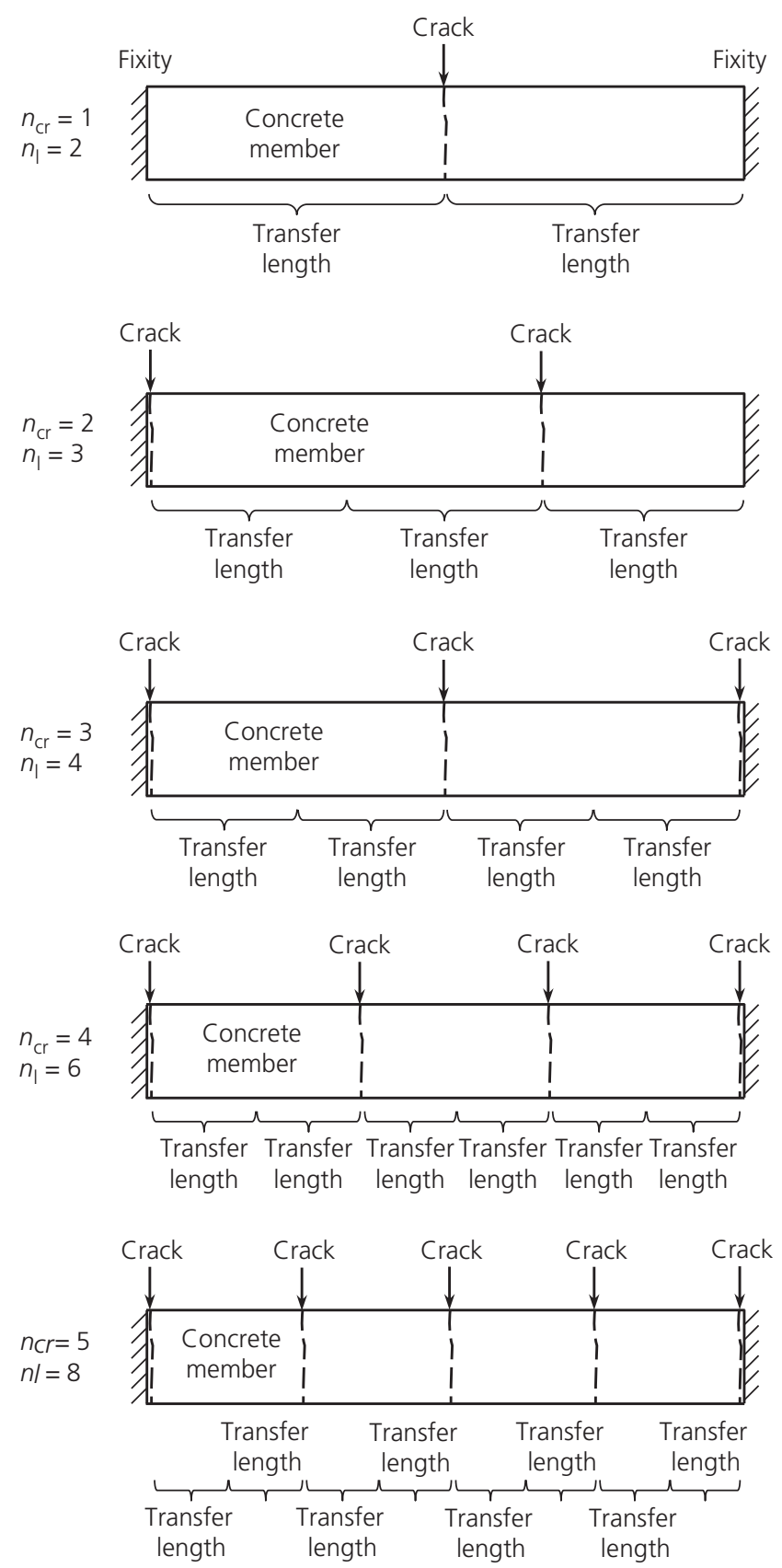

Figure 5. Number of cracks and number of transfer lengths

From this inequality, the upper limit of $l$, denoted $l^{*}$, is obtained as

34. $\quad l^{*}=\left(\frac{1}{m \rho \psi}\right)\left(\frac{\tanh (\psi l) f_{\mathrm{ct}}}{E_{\mathrm{c}}\left[(\Delta u / L)-\varepsilon_{\mathrm{cs}}\right][1-(1 / \cosh (\psi l))]-f_{\mathrm{ct}}}\right)$

In most cases, $\psi l \geq 3 \cdot 0, \tanh (\psi l) \approx 1 \cdot 0$ and $1 / \cosh (\psi l)<0 \cdot 1$, and the exact value of $\psi l$ has little effect on the value of $l^{*}$.
Adopting the arguments of Häußler-Combe and Hartig (2012), the crack spacing $s_{\mathrm{r}}$ has to satisfy the condition

35. $l^{*} \leq s_{\mathrm{r}} \leq 2 l^{*}$

Hence, the crack spacing $s_{\mathrm{r}}$ could vary between $l^{*}$ and $2 l^{*}$ and the transfer length $l$, which is equal to half the crack spacing, could vary between $0 \cdot 5 l^{*}$ and $l^{*}$.

The crack width is related to the crack spacing and the transfer length. However, the crack spacing is sometimes undefined but the transfer length is always well defined, as illustrated in Figure 5. For instance, when there is only one crack within the length of the member, the crack spacing is undefined but there will be two transfer lengths with a mean transfer length equal to half the length of the member. When there is one crack within the length and another crack at one end of the member, there is only one crack spacing between the two cracks and the mean crack spacing is difficult to define, whereas there will be three transfer lengths with a mean transfer length of one-third the length of the member. In fact, the crack width is related more to the transfer length than the crack spacing. From Equation 30, it can be seen that the maximum bond slip $\xi$ is directly related to the transfer length $l$, not the crack spacing $s_{\mathrm{r}}$. For a crack within the length of the member, the crack width is equal to $2 \xi$ because there are bond slips of concrete away from the crack at both sides, whereas for a crack at the end of the member, the crack width is equal to $\xi$ because there is bond slip of concrete away from the crack at only one side.

It is thus suggested that we should work with the transfer length, rather than the crack spacing. Let the number of cracks be $n_{\mathrm{cr}}$. Each crack within the length of the member would produce two transfer lengths, while each crack at the end of the member would produce only one transfer length. Assuming that the first crack would be formed within the length, the second crack would be formed at one end, the third crack would be formed at the other end and subsequent cracks would be formed within the length again, the number of transfer lengths $n_{1}$ may be determined as

36. $n_{1}=2 n_{\mathrm{cr}}-\min \left(n_{\mathrm{cr}}-1,2\right)$

From the number of transfer lengths $n_{1}$ so determined, the mean transfer length $l$ may be evaluated as

37. $l=\frac{L}{n_{1}}=\frac{L}{2 n_{\mathrm{cr}}-\min \left(n_{\mathrm{cr}}-1,2\right)}$

The actual number of cracks $n_{\mathrm{cr}}$ should be taken as the smallest integer value such that the mean transfer length $l$ 
evaluated using Equation 37 satisfies the condition $l \leq l^{*}$ (so as to ensure that the maximum concrete stress $\sigma_{\mathrm{c}}(l)$ is not larger than the concrete tensile strength $f_{\mathrm{ct}}$ ). Then, the mean transfer length $l$ may be substituted into Equation 30 to evaluate the mean value of $\xi$. With the mean value of $\xi$ so evaluated, the total crack width may be calculated as the number of transfer lengths $n_{1}$ times the mean value of $\xi$. Finally, the mean crack width $w$ may be evaluated as the total crack width divided by the number of cracks, or simply as $\left(n_{1} / n_{\mathrm{cr}}\right) \xi$. Multiplying Equation 30 by $n_{1} / n_{\mathrm{cr}}$ the mean crack width $w$ is obtained as

38. $\quad w=\frac{1+m \rho}{1+(m \rho \psi l / \tanh (\psi l))}\left(\frac{\Delta u}{L}-\varepsilon_{\mathrm{cs}}\right)\left(\frac{L}{n_{\mathrm{cr}}}\right)$

Having completed the formulation, it is noted that the analytical solutions derived above are closed-form in nature and are not dependent on any assumed empirical coefficients.

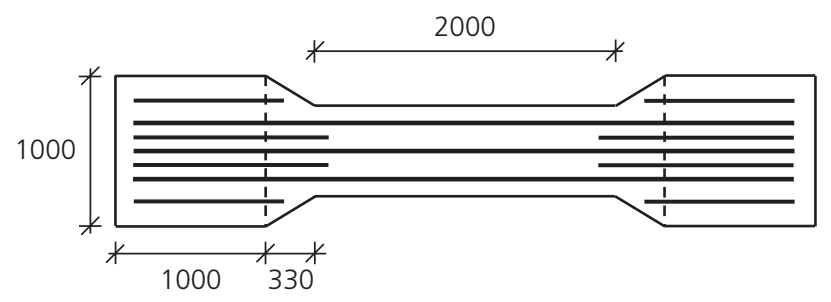

Plan

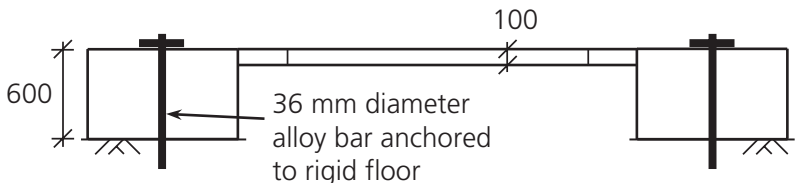

Elevation

Figure 6. Details of concrete slab specimens tested by Nejadi and Gilbert (2004); dimensions in $\mathrm{mm}$

\section{Analysis of test specimens}

To validate the new analytical model, the RC slab specimens tested by Nejadi and Gilbert (2004) were analysed. The dimensions and details of the specimens are shown in Figure 6 and listed in Table 1. Each specimen consisted of a $600 \mathrm{~mm}$ wide by $2000 \mathrm{~mm}$ long prismatic portion connected monolithically via two $330 \mathrm{~mm}$ long splayed portions to end blocks of $1.0 \mathrm{~m}$ by $1.0 \mathrm{~m}$ by $0.6 \mathrm{~m}$ depth at the ends. The end blocks were firmly clamped to a rigid floor to provide effective restraints to the shrinkage movement of the prismatic portion. The splayed portions, having the same depth, were to avoid stress concentration. A total of eight specimens reinforced with two to four steel bars of $10-12 \mathrm{~mm}$ diameter were tested. At the midlength of each specimen, two $75 \mathrm{~mm}$ wide full-depth notches were formed at the two sides during concrete casting to induce the first crack there.

The eight specimens were cast from two batches of concrete. The material properties of each batch of concrete (compressive strength, tensile strength, elastic modulus, shrinkage strain and creep coefficient) as reported by Nejadi and Gilbert (2004) are presented in Table 2. The specimens were kept undisturbed and the number of cracks, the crack spacing, crack width and steel strain of each specimen were measured. Furthermore, due to shrinkage and fixity of the end blocks, the prismatic portion of each specimen was elongated and the elongation of each specimen was measured. The elongation, number of cracks, mean crack spacing and crack width, and maximum steel and concrete stresses (derived from the measured steel strains) as reported by Nejadi and Gilbert (2004), are listed in Table 3.

These specimens were also analysed by Nejadi and Gilbert (2004) and by Häußler-Combe and Hartig (2012) using their own analytical models. The respective analysis results are summarised in Tables 4 and 5 (note that in both tables, the number of cracks includes the artificially induced crack at the middle). It can be seen that both models predict that specimens S1a and S1b should have the largest number of cracks and the smallest mean crack width, whereas specimens S3a

\begin{tabular}{|c|c|c|c|c|c|}
\hline Specimen & Concrete & Number of steel bars, $n$ & Steel bar diameter, $\phi: \mathrm{mm}$ & Steel area, $A_{s}: \mathrm{mm}^{2}$ & Concrete depth: $\mathrm{mm}$ \\
\hline S1a & Batch I & 3 & 12 & 339 & $102 \cdot 2$ \\
\hline s1b & Batch I & 3 & 12 & 339 & $99 \cdot 8$ \\
\hline S2a & Batch I & 3 & 10 & 236 & $101 \cdot 6$ \\
\hline S2b & Batch II & 3 & 10 & 236 & $98 \cdot 3$ \\
\hline S3a & Batch I & 2 & 10 & 157 & $99 \cdot 2$ \\
\hline$S 3 b$ & Batch I & 2 & 10 & 157 & $99 \cdot 3$ \\
\hline S4a & Batch I & 4 & 10 & 314 & $100 \cdot 5$ \\
\hline$S 4 b$ & Batch I & 4 & 10 & 314 & $101 \cdot 1$ \\
\hline
\end{tabular}

Table 1. Dimensions and details of specimens tested by Nejadi and Gilbert (2004) 
and S3b should have the smallest number of cracks and the largest mean crack width. These predictions agree fairly well with the experimental results. However, the model of Nejadi and Gilbert (2004) predicts that the maximum steel stress in specimens S3a and S3b should be around 553-562 MPa, but the model of Häußler-Combe and Hartig (2012) predicts that the maximum steel stress in specimens $\mathrm{S} 3 \mathrm{a}$ and $\mathrm{S} 3 \mathrm{~b}$ should be around 499-503 MPa. Moreover, the Nejadi and Gilbert (2004) model predicts that the maximum concrete stress should vary from 1.22 to $1.68 \mathrm{MPa}$ but the Häußler-Combe and Hartig (2012) model predicts that the maximum concrete stress should remain constant at $1.97 \mathrm{MPa}$. The two models thus do not quite agree.

The specimens were also analysed using the new analytical model presented here. In conducting the analysis, the materials properties reported by Nejadi and Gilbert (2004) were used. Regarding the steel properties, the elastic modulus was assumed to be $200 \mathrm{GPa}$ and the yield strength was assumed to be high enough to avoid yielding. The concrete was assumed to be linearly elastic, with its tensile strength and elastic modulus as given in Table 2. Regarding the bond properties, the bond stiffness $k_{\mathrm{b}}$ was taken as the mean secant stiffness evaluated using Equation 2. Since the mean secant stiffness is dependent on the maximum bond slip, it was determined by

\begin{tabular}{lcc}
\hline Concrete material properties & Batch I & Batch II \\
\hline Compressive strength at $28 \mathrm{~d}: \mathrm{MPa}$ & $24 \cdot 3$ & $28 \cdot 4$ \\
Tensile strength at $28 \mathrm{~d}: \mathrm{MPa}$ & $1 \cdot 97$ & $2 \cdot 10$ \\
Elastic modulus at $28 \mathrm{~d}: \mathrm{MPa}$ & 22810 & 23210 \\
Shrinkage strain at $122 \mathrm{~d}: \mu \varepsilon$ & 457 & 495 \\
Creep coefficient at $122 \mathrm{~d}$ & 0.98 & $1 \cdot 16$
\end{tabular}

Table 2. Concrete material properties of Nejadi and Gilbert (2004) test specimens an iterative process. First, it was evaluated as that corresponding to a maximum bond slip of $0 \cdot 15 \mathrm{~mm}$. Then, it was used to conduct shrinkage cracking analysis, from which the maximum bond slip was obtained. The maximum bond slip so obtained was used to re-evaluate the mean secant stiffness so as to obtain an updated value. The updated mean secant stiffness was then used to conduct the shrinkage cracking analysis again, and the analysis was repeated. For all the specimens analysed, the mean secant stiffness converged rapidly and only two or three iterations were needed to obtain convergent results. The analytical results obtained by this new model are given in Table 6, where the mean transfer length instead of the mean crack spacing is presented.

To facilitate the comparison, the experimental crack widths and crack widths from the three analytical models are listed together in Table 7. The table shows that there is a very large discrepancy between the experimental crack width of specimen S3a and the corresponding crack widths from all three analytical models. For specimen S3a, the experimental crack width of $0.84 \mathrm{~mm}$ appears to be exceptionally large, bearing in mind that the analytical crack widths obtained by the three models are all within 0.51 to $0.56 \mathrm{~mm}$. The experimental results reveal that, for this particular specimen, there was only one crack in the middle and the maximum steel stress at the crack was as high as $532 \mathrm{MPa}$. Hence, there is a strong possibility that the steel bars in this specimen had yielded during cracking, thus causing the formation of a very wide crack. Particular care is therefore needed when interpreting the experimental results of specimen S3a.

For an assessment of accuracy, the percentage errors of the mean crack width predictions by the three analytical models were evaluated and these are also presented in Table 7 . With all specimens included, the mean absolute errors of the mean crack width predictions by the models of Nejadi and Gilbert (2004) and Häußler-Combe and Hartig (2012) and the new model are $15 \cdot 6 \%, 19 \cdot 1 \%$ and $13 \cdot 7 \%$, respectively. With specimen S3a excluded, the mean absolute errors are $12 \cdot 3 \%, 16 \cdot 8 \%$

\begin{tabular}{lcccccc}
\hline $\begin{array}{c}\text { Specimen } \\
\text { Elongation, } \Delta u: \\
\mathrm{mm}\end{array}$ & $\begin{array}{c}\text { Number of } \\
\text { cracks }\end{array}$ & $\begin{array}{c}\text { Mean crack } \\
\text { spacing: mm }\end{array}$ & $\begin{array}{c}\text { Mean crack } \\
\text { width: mm }\end{array}$ & $\begin{array}{c}\text { Maximum steel } \\
\text { stress: MPa }\end{array}$ & $\begin{array}{c}\text { Maximum concrete } \\
\text { stress: MPa }\end{array}$ \\
\hline S1a & 0.305 & 4 & 670 & 0.21 & 273 & 1.77 \\
S1b & 0.383 & 4 & 403 & $0 \cdot 18$ & 190 & 1.41 \\
S2a & 0.309 & 3 & 674 & 0.30 & 250 & 1.13 \\
S2b & 0.315 & 3 & 700 & 0.31 & 290 & 1.46 \\
S3a & 0.402 & 1 & Undefined & 0.84 & 532 & 1.45 \\
S3b & 0.419 & 2 & 997 & 0.50 & 467 & 1.31 \\
S4a & 0.245 & 3 & 783 & 0.23 & 270 & 1.64 \\
S4b & 0.162 & 3 & 995 & 0.25 & 276 & 1.71
\end{tabular}

Table 3. Experimental results reported by Nejadi and Gilbert (2004) 


\begin{tabular}{lccccc} 
Specimen & $\begin{array}{c}\text { Number } \\
\text { of cracks }\end{array}$ & $\begin{array}{c}\text { Mean crack } \\
\text { spacing: mm }\end{array}$ & $\begin{array}{c}\text { Mean crack } \\
\text { width: mm }\end{array}$ & $\begin{array}{c}\text { Maximum steel } \\
\text { stress: MPa }\end{array}$ & $\begin{array}{c}\text { Maximum concrete } \\
\text { stress: MPa }\end{array}$ \\
\hline S1a & 4 & 667 & 0.19 & 246 & 1.68 \\
S1b & 5 & 500 & 0.16 & 196 & 1.43 \\
S2a & 3 & 1000 & 0.28 & 337 & 1.54 \\
S2b & 4 & 667 & 0.26 & 235 & 1.22 \\
S3a & 1 & Undefined & 0.51 & 553 & 1.63 \\
S3b & 1 & Undefined & 0.50 & 562 & 1.65 \\
S4a & 4 & 667 & 0.18 & 261 & 1.66 \\
S4b & 4 & 667 & 0.20 & 227 & 1.47
\end{tabular}

Table 4. Analytical results reported by Nejadi and Gilbert (2004)

\begin{tabular}{llcccc}
\hline Specimen & $\begin{array}{l}\text { Number } \\
\text { of cracks }\end{array}$ & $\begin{array}{c}\text { Mean crack } \\
\text { spacing: mm }\end{array}$ & $\begin{array}{c}\text { Mean crack } \\
\text { width: mm }\end{array}$ & $\begin{array}{c}\text { Maximum steel } \\
\text { stress: MPa }\end{array}$ & $\begin{array}{c}\text { Maximum concrete } \\
\text { stress: MPa }\end{array}$ \\
\hline S1a & 5 & 500 & 0.25 & 275 & 1.97 \\
S1b & 5 & 500 & 0.26 & 289 & 1.97 \\
S2a & 4 & 667 & 0.33 & 369 & 1.97 \\
S2b & - & - & - & - & - \\
S3a & 3 & 1000 & 0.56 & 599 & 1.97 \\
S3b & 3 & 1000 & 0.56 & 295 & 1.97 \\
S4a & 5 & 500 & 0.23 & 279 & 1.97 \\
S4b & 5 & 500 & 0.21 & & 1.97
\end{tabular}

Table 5. Analytical results reported by Häußler-Combe and Hartig (2012)

\begin{tabular}{lccccc}
\hline Specimen & $\begin{array}{c}\text { Number of } \\
\text { cracks }\end{array}$ & $\begin{array}{c}\text { Mean transfer length: } \\
\mathrm{mm}\end{array}$ & $\begin{array}{c}\text { Mean crack width: } \\
\mathrm{mm}\end{array}$ & $\begin{array}{c}\text { Maximum steel stress: } \\
\text { MPa }\end{array}$ & $\begin{array}{c}\text { Maximum concrete stress: } \\
\text { MPa }\end{array}$ \\
\hline S1a & 4 & 333 & 0.24 & 301 & 1.91 \\
S1b & 5 & 250 & 0.22 & 242 & 1.55 \\
S2a & 3 & 500 & 0.32 & 435 & 1.89 \\
S2b & 3 & 500 & 0.33 & 463 & 2.08 \\
S3a & 2 & 667 & 0.53 & 596 & 1.73 \\
S3b & 2 & 667 & 0.54 & 603 & 1.74 \\
S4a & 4 & 250 & 0.23 & 298 & 1.80 \\
S4b & 4 & 333 & 0.21 & 277 & 1.70
\end{tabular}

Table 6. Analytical results using the new analytical model

and $10 \cdot 4 \%$, respectively. Hence, based on the mean absolute errors, the new model has slightly better accuracy. Moreover, with specimen S3a excluded, the mean errors of the mean crack width predictions by the three models are $-12.3 \%$, $+11 \cdot 5 \%$ and $+5 \cdot 7 \%$, respectively. Hence, the model of Nejadi and Gilbert (2004) tends to underestimate the mean crack width, the Häußler-Combe and Hartig (2012) model tends to overestimate the mean crack width, whereas the new model has insignificant tendency to either overestimate or underestimate the mean crack width (bearing in mind that the errors of predictions by the new model are partly due to experimental errors).

\section{Conclusions}

Existing analytical models for shrinkage cracking analysis of RC members have been reviewed and, in order to avoid reliance on 


\begin{tabular}{|c|c|c|c|c|c|c|c|}
\hline \multirow[t]{2}{*}{ Specimen } & \multirow[t]{2}{*}{$w_{\text {exp }}: m m$} & \multicolumn{2}{|c|}{$\begin{array}{l}\text { Model of Nejadi and } \\
\text { Gilbert (2004) }\end{array}$} & \multicolumn{2}{|c|}{$\begin{array}{l}\text { Model of Häußler-Combe } \\
\text { and Hartig (2012) }\end{array}$} & \multicolumn{2}{|c|}{ New analytical model } \\
\hline & & w: mm & Error: \% & w: $\mathrm{mm}$ & Error: \% & $w: \mathrm{mm}$ & Error: \% \\
\hline S1a & $0 \cdot 21$ & $0 \cdot 19$ & -10 & $0 \cdot 25$ & +19 & 0.24 & +14 \\
\hline S1b & $0 \cdot 18$ & $0 \cdot 16$ & -11 & $0 \cdot 26$ & +44 & $0 \cdot 22$ & +22 \\
\hline$S 2 a$ & $0 \cdot 30$ & $0 \cdot 28$ & -7 & 0.33 & +10 & $0 \cdot 32$ & +7 \\
\hline$S 2 b$ & $0 \cdot 31$ & $0 \cdot 26$ & -16 & Not ana & & 0.33 & +6 \\
\hline S3a & $0 \cdot 84$ & $0 \cdot 51$ & -39 & 0.56 & -33 & 0.53 & -37 \\
\hline S3b & $0 \cdot 50$ & $0 \cdot 50$ & 0 & $0 \cdot 56$ & +12 & 0.54 & +8 \\
\hline S4a & $0 \cdot 23$ & $0 \cdot 18$ & -22 & $0 \cdot 23$ & 0 & 0.23 & 0 \\
\hline S4b & $0 \cdot 25$ & $0 \cdot 20$ & -20 & $0 \cdot 21$ & -16 & $0 \cdot 21$ & -16 \\
\hline \multicolumn{3}{|c|}{$\begin{array}{l}\text { Mean absolute error } \\
\text { (with all specimens included): \% }\end{array}$} & $15 \cdot 6$ & & $19 \cdot 1$ & & $13 \cdot 7$ \\
\hline \multicolumn{3}{|c|}{ Mean absolute error (with S3a excluded): \% } & $12 \cdot 3$ & & $16 \cdot 8$ & & $10 \cdot 4$ \\
\hline \multicolumn{3}{|c|}{ Mean error (with S3a excluded): \% } & $-12 \cdot 3$ & & $+11 \cdot 5$ & & $+5 \cdot 7$ \\
\hline
\end{tabular}

Table 7. Comparison of experimental ( $\left.W_{\text {exp }}\right)$ and analytical mean crack widths $(w)$

empirical coefficients, a new and more rigorous analytical model was developed. The new model was formulated purely based on the mechanics of the steel bar-concrete interaction. From the formulation, two governing equations, which are second-order partial differential equations, were derived. With the bond stress-slip relation taken into account and the boundary conditions duly considered, the governing equations can be solved analytically without making any assumptions on the concrete, steel and bond stress distributions along the transfer length. In fact, the actual concrete, steel and bond stress distributions are evaluated as an integral part of the solution. The new model is therefore mathematically more rigorous than the existing models. Moreover, closed-form solutions are obtained, from which the effects of various parameters on the crack spacing and crack width may be evaluated algebraically, and the crack-control steel designed to meet the crack width requirements.

Apart from giving closed-form solutions, the new model has the unique feature that it works with the transfer length, rather than the crack spacing, which is sometimes undefined. Nevertheless, as with the existing models, it still considers the number of cracks. Basically, from the number of cracks, the number of transfer lengths is determined and the mean transfer length, which governs the maximum concrete stress, is evaluated. The number of cracks is taken as the smallest integer value such that the mean transfer length is not larger than the upper limit of the transfer length or the maximum concrete stress is not larger than the concrete tensile strength.

For validation and comparison with the existing models, the new model was applied to analyse eight specimens tested by Nejadi and Gilbert (2004). Due to randomness of cracking, there are occasionally significant errors in the predicted crack numbers and crack widths. Nevertheless, based on the absolute errors, the new model has slightly better accuracy in crack width prediction than the existing models. Moreover, based on the mean errors, the new model has the smallest tendency to over- or underestimate the crack width. Lastly, it is emphasised that the new model, which does not rely on any assumed values of empirical coefficients, should be more generally applicable. However, the theoretical predictions by the new model have been compared with only a limited number of experimental results and comparison with more experimental results for further verification is recommended.

\section{Appendix: Solving the governing equations of concrete cracking}

The governing equation (Equation 26) may be split into the following two equations

39. $\frac{\partial^{2} u_{\mathrm{c}}}{\partial x^{2}}=-m \rho \frac{\partial^{2} u_{\mathrm{s}}}{\partial x^{2}}$

40. $\frac{\partial^{2} u_{\mathrm{c}}}{\partial x^{2}}=\lambda\left(u_{\mathrm{c}}-u_{\mathrm{s}}\right)$

The solution procedures start with the following general solutions, in which $\psi_{1}$ and $\psi_{2}$ are the roots of the characteristic equation, and $A, B, C$ and $D$ and $\underline{A}, \underline{B}, \underline{C}$ and $\underline{D}$ are coefficients to be determined from the boundary conditions.

41. $u_{\mathrm{c}}=A \mathrm{e}^{\psi_{1} x}+B \mathrm{e}^{\psi_{2} x}+C x+D$ 
42. $u_{\mathrm{s}}=\underline{A} \mathrm{e}^{\psi_{1} x}+\underline{B} \mathrm{e}^{\psi_{2} x}+\underline{C} x+\underline{D}$

Substituting into Equations 39 and 40, the following equations are obtained

43.

$$
\begin{aligned}
& A=-m \rho \underline{A} \\
& B=-m \rho \underline{B} \\
& C=\underline{C} \\
& D=\underline{D}
\end{aligned}
$$

$$
\psi_{1}^{2}=\frac{\lambda(1+m \rho)}{m \rho}
$$

$$
\psi_{2}^{2}=\frac{\lambda(1+m \rho)}{m \rho}
$$

The characteristic equation (Equation 44 ) has two roots, $\psi_{1}$ and $\psi_{2}$. Let the parameter $\psi$ be defined by

45. $\psi=\sqrt{\frac{\lambda(1+m \rho)}{m \rho}}$

The two roots of the characteristic equation are given by

46. $\psi_{1}=\psi$

47. $\psi_{2}=-\psi$

Substituting into Equations 41 and 42, the displacement functions are obtained as

48. $u_{\mathrm{c}}=-m \rho \underline{A} \mathrm{e}^{\psi_{1} x}-m \rho \underline{B} \mathrm{e}^{\psi_{2} x}+\underline{C} x+\underline{D}$

49. $u_{\mathrm{s}}=\underline{A}^{\psi_{1} x}+B \mathrm{e}^{\psi_{2} x}+C \underline{C x}+\underline{D}$

The boundary conditions that $u_{\mathrm{c}}(0)=\xi$ and $u_{\mathrm{s}}(0)=0$ at $x=0$ lead to

50. $\quad u_{\mathrm{c}}(0)=-m \rho \underline{A}-m \rho \underline{B}+\underline{D}=\xi$

51. $u_{\mathrm{s}}(0)=\underline{A}+\underline{B}+\underline{D}=0$
Likewise, the boundary conditions that $u_{\mathrm{c}}(l)=(\Delta u / L) l$ and $u_{\mathrm{s}}(l)=(\Delta u / L) l$ at $x=l$ lead to

52. $u_{\mathrm{c}}(l)=-m \rho \underline{A} \mathrm{e}^{\psi_{1} l}-m \rho \underline{B} \mathrm{e}^{\psi_{2} l}+\underline{C} l+\underline{D}=(\Delta u / L) l$

53. $u_{\mathrm{s}}(l)=\underline{A} \mathrm{e}^{\psi_{1} l}+\underline{B} \mathrm{e}^{\psi_{2} l}+\underline{C l}+\underline{D}=(\Delta u / L) l$

Solving Equations $50-53$ yields

54. $\quad \underline{A}=\frac{\xi}{1+m \rho} \cdot \frac{\mathrm{e}^{\psi_{2} l}}{\mathrm{e}^{\psi_{1} l}-\mathrm{e}^{\psi_{2} l}}$

55. $\quad \underline{B}=\frac{-\xi}{1+m \rho} \cdot \frac{\mathrm{e}^{\psi_{1} l}}{\mathrm{e}^{\psi_{1} l}-\mathrm{e}^{\psi_{2} l}}$

56. $\quad \underline{C}=\frac{\Delta u}{L}-\frac{\xi / l}{1+m \rho}$

57. $\quad \underline{D}=\frac{\xi}{1+m \rho}$

Substituting into Equations 48 and 49 then yields

58. $u_{\mathrm{c}}=\frac{\Delta u}{L} x+\frac{\xi}{1+m \rho}\left(-m \rho \frac{\mathrm{e}^{\psi_{2} l} \mathrm{e}^{\psi_{1} x}-\mathrm{e}^{\psi_{1} l} \mathrm{e}^{\psi_{2} x}}{\mathrm{e}^{\psi_{1} l}-\mathrm{e}^{\psi_{2} l}}-\frac{x}{l}+1\right)$

59. $u_{\mathrm{s}}=\frac{\Delta u}{L} x+\frac{\xi}{1+m \rho}\left(\frac{\mathrm{e}^{\psi_{2} l} \mathrm{e}^{\psi_{1} x}-\mathrm{e}^{\psi_{1} l} \mathrm{e}^{\psi_{2} x}}{\mathrm{e}^{\psi_{1} l}-\mathrm{e}^{\psi_{2} l} l}-\frac{x}{l}+1\right)$

From the above displacement functions, the concrete and steel stresses are obtained as

60. $\sigma_{\mathrm{c}}(x)=E_{\mathrm{c}}\left(\frac{\Delta u}{L}-\varepsilon_{\mathrm{cs}}-\xi \cdot \frac{m \rho \psi}{1+m \rho} \cdot \frac{\cosh (\psi(l-x))}{\sinh (\psi l)}-\xi \cdot \frac{1 / l}{1+m \rho}\right)$

61. $\sigma_{\mathrm{s}}(x)=E_{\mathrm{s}}\left(\frac{\Delta u}{L}+\xi \cdot \frac{\psi}{1+m \rho} \cdot \frac{\cosh (\psi(l-x))}{\sinh (\psi l)}-\xi \cdot \frac{1 / l}{1+m \rho}\right)$ 


\section{REFERENCES}

BSI (1987) BS 8007:1987: Code of practice for design of concrete structures for retaining aqueous liquids. BSI, London, UK.

Castel A and Gilbert RI (2014) Influence of time-dependent effects on the crack spacing in reinforced concrete beams. Structural Concrete 15(3): 373-379.

CEB (Comité Euro-International du Béton) (1993) CEB-FIP Model Code 1990: Model Code for Concrete Structures. Thomas Telford, London, UK.

Gilbert RI (1992) Shrinkage cracking in fully restrained concrete members. ACI Structural Journal 89(2): 141-149.

Gilbert RI (2001) Shrinkage, cracking and deflection - the serviceability of concrete structures. Electronic Journal of Structural Engineering 1: 15-37.

Gilbert RI (2003) Shrinkage cracking and crack control in fully-restrained reinforced concrete members. In System-based Vision for Strategic and Creative Design: Proceedings of the Second International Conference on Structural and Construction Engineering, Rome, Italy (Bontempi F (ed.)). Swets and Zeitlinger, Lisse, the Netherlands, pp. 1921-1927.

Gilbert RI and Ranzi G (2011) Time-Dependent Behaviour of Concrete Structures. Spon Press, Abingdon, UK.

Häußler-Combe $U$ and Hartig J (2012) Evaluation of concrete cracking due to restrained thermal loading and shrinkage. ACI Structural Journal 109(1): 41-51.

Hughes BP (1971a) Control of Thermal and Shrinkage Cracking in Restrained Reinforced Concrete Walls. Construction Industry Research and Information Association, London, UK, CIRIA Technical Note 21.

Hughes BP (1971b) Elimination of Shrinkage and Thermal Cracking in a Water-Retaining Structure. Construction Industry Research and Information Association, London, UK, CIRIA Technical Note 36.

Jurkiewiez B, Destrebecq JF and Vergne A (1999) Incremental analysis of time-dependent effects in composite structures. Computers and Structures 73(1-5): 425-435.

Kwan AKH and Ng PL (2009) Shrinkage movement analysis of reinforced concrete floors constructed in stages. Computers and Concrete 6(2): 167-185.
Kwan AKH and Ng PL (2015) Remnant creep based visco-elastic model for concrete creep analysis. Proceedings of the Institution of Civil Engineers - Structures and Buildings 168(1): 3-14, http://dx.doi.org/10.1680/stbu. 13.00028 .

Kwan AKH, Au FTK and Lee PKK (2002) Minimizing shrinkage cracks in concrete structures for better serviceability and durability. Proceedings of Innovative Buildings Symposium, Hong Kong. The Hong Kong Institution of Engineers, Hong Kong, China, pp. 117-136.

Kwan AKH, Au FTK and Lee PKK (2003) High-performance concrete buildings for the new millennium. Progress in Structural Engineering and Materials 5(4): 263-273.

Kwan AKH, Au FTK, Wong HHC and Ng PL (2010) Shrinkage of Hong Kong granite aggregate concrete. Magazine of Concrete Research 62(2): 115-126, http://dx.doi.org/ 10.1680/macr.2008.62.2.115.

Liu CH, Au FTK and Lee PKK (2006) Estimation of shrinkage effects on reinforced concrete podiums. HKIE Transactions 13(4): 33-43.

Ma FJ and Kwan AKH (2015) Crack width analysis of reinforced concrete members under flexure by finite element method and crack queuing algorithm. Engineering Structures 105: 209-219.

Nejadi S and Gilbert RI (2004) Shrinkage cracking and crack control in restrained reinforced concrete members. $A C I$ Structural Journal 101(6): 840-845.

Neville AM (1955) Theories of creep in concrete. ACI Journal 52(9): 47-60.

Neville AM (1958) The influence of cement on creep of concrete and mortar. PCI Journal 2(1): 12-18.

Neville AM (2011) Properties of Concrete, 5th edn. Pearson, Harlow, UK.

Powers TC (1968) Mechanisms of shrinkage and reversible creep of hardened Portland cement paste. Proceedings of International Conference on the Structure of Concrete, London, UK. Cement and Concrete Association, Slough, UK, pp. 319-344.

Vandamme M and UIm FJ (2009) Nanogranular origin of concrete creep. Proceedings of the National Academy of Sciences 106(26): 10552-10557. 